\title{
Judicialização do acesso ao tratamento de doenças genéticas raras: a doença de Fabry no Rio Grande do Sul
}

\author{
Court-ordered access to treatment of rare genetic diseases: \\ Fabry Disease in the state of Rio Grande do Sul, Brazil
}

\author{
Dailor Sartori Junior ${ }^{1}$ \\ Paulo Gilberto Cogo Leivas ${ }^{2}$ \\ Mônica Vinhas de Souza ${ }^{3}$ \\ Bárbara Corrêa Krug ${ }^{3}$ \\ Giacomo Balbinotto ${ }^{4}$ \\ Ida Vanessa Doederlein Schwartz ${ }^{5}$
}

${ }^{1}$ Serviço de Genética Médica, Hospital de Clínicas de Porto Alegre, Universidade Federal do Rio Grande do Sul. R. Ramiro Barcelos 2350, Rio Branco. 90035-003 Porto Alegre RS.

ischwartz@hcpa.ufrgs.br ${ }^{2}$ Centro Universitário Ritter dos Reis.

${ }^{3}$ Programa de Pós-

Graduação em Medicina, Ciências Médicas,

Universidade Federal do Rio Grande do Sul.

${ }^{4}$ Departamento de Ciências Econômicas, Faculdade de

Ciências Econômicas,

Universidade Federal do

Rio Grande do Sul.

${ }^{5}$ Departamento de Genética, Universidade Federal do

Rio Grande do Sul.
Abstract Court-ordered access to high-cost drugs for rare genetic diseases, such as Fabry Disease (alpha-galactosidase-A deficiency), is a growing phenomenon as yet lacking systematic study. An observational, cross-sectional and retrospective study was conducted to characterize the lawsuits related to access to treatment for Fabry Disease by Enzyme Replacement Therapy in the State of Rio Grande do Sul prior to 2007. The study identified 13 lawsuits and 17 plaintiffs, 11 requesting alfa and 6 betagalsidase. The State of RS, the Federal Government, and 5 municipalities figured as defendants, in the form of joinder of parties or otherwise. There were 13 requests for interlocutory relief of which 12 were granted, and 2 sentences were handed down, both favorable. "Risk of death" was alleged by doctors in 4 prescriptions and by lawyers in the 13 lawsuits. The data suggest the lack of discussions combining aspects of medical efficacy and safety, cost-effectiveness, economic impact, and legal and constitutional arguments, which requires a specific policy for rare genetic diseases to standardize access to treatment.

Key words Fabry disease, Government judiciary, Pharmaceutical care
Resumo A judicialização do acesso a medicamentos de alto custo para doenças genéticas raras, como a doença de Fabry (deficiência de alfa-galactosidase A), é um fenômeno crescente e pouco estudado de forma sistemática. Realizou-se um estudo observacional, transversal e retrospectivo para caracterizar as ações judiciais relativas ao acesso ao tratamento da doença de Fabry por terapia de reposição enzimática no estado do Rio Grande do Sul até 2007. Foram identificadas 13 ações e 17 demandantes. Onze solicitaram alfa e 6 betagalsidase. Figuraram como réus o estado do RS, a União e 5 municípios, em litisconsórcio ou não. Houve 13 pedidos de antecipação da tutela, 12 concedidos, e 2 sentenças, ambas procedentes. "Risco de morte" foi alegado, por médicos, em 4 prescrições $e$, por advogados, nas 13 ações. Os dados sugerem a ausência de discussões que envolvam conjuntamente aspectos de eficácia e segurança médicas, custoefetividade, impacto econômico e argumentos jurídico-constitucionais, sendo necessária uma política específica para doenças genéticas raras que padronize o acesso aos tratamentos.

Palavras-chave Doença de Fabry, Poder Judiciário, Assistência farmacêutica 


\section{Introdução}

A doença de Fabry é uma doença genética rara pertencente ao grupo das doenças lisossômicas, de herança ligada ao X, e caracterizada pela atividade deficiente da enzima alfa-galactosidase A. Sua incidência estimada é de 1 em 40.000 a 100.000 indivíduos do sexo masculino ${ }^{1,2}$. No Brasil, o Laboratório de Erros Inatos do Metabolismo do Hospital de Clínicas de Porto Alegre (LREIMHCPA), referência nacional para doenças lisossômicas, diagnosticou, no período de 1982 a 2007, 28 pacientes do sexo masculino com esta doença ${ }^{3}$, sendo 9 do Rio Grande do Sul.

Em relação às manifestações clínicas, as principais complicações ocorrem na idade adulta, quando, na maioria dos casos, os pacientes desenvolvem doença cardíaca e renal graves. Disfunção renal progressiva é a causa de óbito mais frequente ${ }^{4}$. O tratamento específico é realizado por terapia de reposição enzimática (TRE), estratégia de tratamento de alto custo que consiste na administração periódica de enzima sintética (no caso, betagalsidase ou alfagalsidase) semelhante à enzima cuja atividade está deficiente no paciente (no caso, a alfa-galactosidase A).

A betagalsidase, produzida no período da coleta de dados pela Genzyme Corporation (EUA), empresa comprada pela francesa Sanofi-Aventis em fevereiro de 2011, possui aprovação pelo U.S. Food and Drug Administration (FDA) e European Medicines Agency (EMA) (agências reguladoras americana e europeia, respectivamente) desde 2003, além de ter sido a primeira a obter registro na Agência Nacional de Vigilância Sanitária (Anvisa), em 2006. A alfagalsidase, produzida pelo laboratório Shire HGT (EUA), foi licenciada apenas pela EMA, não pelo FDA e teve seu registro aprovado no Brasil, em novembro de 2009. Em que pese a existência de registro no Brasil, a beta e a alfagalsidase não fazem parte de programa ou lista do Sistema Único de Saúde (SUS), consequentemente, não integram o componente especializado de assistência farmacêutica do Ministério da Saúde (MS), inexistindo, portanto, protocolos clínicos do MS balizando o seu uso ${ }^{5}$.

No Brasil, o governo regula o ciclo de vida das tecnologias em saúde através da Anvisa, do MS, da Agência Nacional de Saúde Suplementar (ANS) e da Comissão Nacional de Incorporação de Tecnologias no SUS (CONITEC), todos locais privilegiados das atividades subsidiáveis pela avaliação de tecnologias em saúde (ATS) ${ }^{6}$. Apesar da existência desta rede de pesquisa, avaliação e monitoramento de tecnologias, muitas questões ainda precisam ser respondidas no que concerne às doenças (genéticas) raras. A escassez de evidências científicas apropriadas disponíveis, associada ao alto custo dos tratamentos, acaba por dificultar a incorporação destas terapias em políticas públicas consistentes e que garantam acesso padronizado e gratuito às mesmas pela população, transferindo-se assim à Justiça a atribuição de distribuição destas tecnologias ${ }^{7}$.

A Constituição Federal de 1988 incluiu o direito à saúde no seu art. $6^{\circ}$, classificando-o como um direito fundamental social e, segundo a regra do parágrafo primeiro do art. $5^{\circ}$, dotado de aplicabilidade imediata e de eficácia plena. Isto significa reconhecer a importância deste direito em um plano formal, eis que positivado na carta máxima do ordenamento jurídico brasileiro, e em um plano material, devido à importância do bem jurídico tutelado para o exercício de uma vida com dignidade.

O art. 196 refere expressamente a obrigação precípua do Estado na efetivação deste direito, cuja titularidade é de todos, e incumbe a tarefa ao então instituído Sistema Único de Saúde (SUS). Posteriormente, foi promulgada a Lei no 8.080/1990 para regular o novo sistema de saúde pública, reforçando os princípios constitucionais da universalidade, igualdade, integralidade, descentralização e participação social ${ }^{8}$. São estas previsões que fundamentam a busca judicial por medicamentos para as doenças raras.

Levantamento realizado pelo nosso grupo em 2008, por exemplo, a partir de questionários enviados a médicos geneticistas, identificou 40 pacientes brasileiros com doença de Fabry, quatorze deles em tratamento com betagalsidase e $8 \mathrm{com}$ alfagalsidase; dos 15 pacientes cuja informação sobre modo de acesso à terapia era disponível, cinco estavam recebendo a mesma por meio de estudo fase III, cinco por acesso expandido e 5 por ordem judicial.

Pretende-se, com este artigo, elaborar avaliação descritiva, seguida de análise crítica, das ações judiciais que objetivam o tratamento da doença de Fabry por alfagalsidase e betagalsidase no estado do Rio Grande do Sul até dezembro de 2007. Serão enfatizados aspectos médicos, econômicos e jurídicos (legais e constitucionais), para, assim, buscar-se compreender melhor o fenômeno da judicialização do acesso ao tratamento de doenças genéticas raras e contribuir para a melhoria da respectiva assistência farmacêutica. 


\section{Métodos}

O presente estudo é caracterizado como observacional, transversal e retrospectivo, tendo sido aprovado pelo Comitê de Ética e Pesquisa do Hospital de Clínicas de Porto Alegre (HCPA). A amostra foi identificada a partir dos bancos de dados da Secretaria Estadual de Saúde do Rio Grande do Sul (RS) e do MS, sendo incluídas ações judiciais em âmbito estadual - contra o estado ou municípios - e âmbito federal - contra a União -, cujo objetivo fosse o acesso ao tratamento da doença de Fabry com alfagalsidase e betagalsidase no RS, até dezembro de 2007. As ações foram analisadas na fase processual em que se encontravam quando da sua identificação, sem atualizações do seu curso posterior.

Para a coleta de dados e a caracterização quantitativa e qualitativa das demandas, foi elaborado um formulário padrão o qual continha perguntas sobre os demandantes, o medicamento solicitado e sua dosagem, a origem da prescrição - se proveniente de instituição universitária ou não - e a justificativa do médico para prescrever o tratamento. Em relação ao andamento processual, buscou-se dados sobre a justificativa do advogado da parte autora para a propositura da ação, a existência de contestação dos réus, de decisão liminar, de sentença e de recursos, privilegiando a argumentação utilizada pelos atores processuais envolvidos em cada uma destas fases. A análise argumentativa avaliou a presença de três aspectos básicos: médicos e científicos; econômicos; legais e constitucionais.

Cada eixo argumentativo trouxe conceitos e aspectos considerados essenciais para uma discussão qualificada sobre acesso ao tratamento de alto custo para doenças raras. Não houve divisão entre argumentos favoráveis ou desfavoráveis, devido ao fato de determinados argumentos poderem ser usados tanto para a concessão como para a negativa do medicamento. A menção ao princípio da proporcionalidade, por exemplo, não pressupõe que sua conclusão seja para dar primazia ao direito fundamental à saúde do demandante em detrimento da limitação orçamentária do réu. $\mathrm{O}$ que foi considerado, entretanto, foi a existência ou não do conceito no discurso do ator processual.

O preenchimento dos formulários e a revisão dos dados foram executados pela mesma equipe, composta por um profissional médico e três profissionais do direito com formação em economia. Cada processo foi, portanto, revisado quatro vezes, sendo formados quatro instru- mentos preenchidos para o mesmo processo; deste modo, foi garantida a fidelidade dos dados coletados. Os quatro instrumentos foram comparados em uma reunião de consenso. No caso de discordância em relação às questões que envolveram aspectos médicos/científicos, prevaleceu o entendimento do profissional da saúde; no caso de discordância em relação a questões que envolveram aspectos jurídico-econômicos, prevaleceu o entendimento da maioria dos profissionais do direito e economia. $O$ consenso foi transcrito para um banco de dados eletrônico, tendo sido então realizada uma análise estatística de caráter descritivo.

\section{Resultados}

\section{Perfil dos demandantes e das ações judiciais}

A busca realizada identificou 13 processos judiciais que preenchiam os critérios de inclusão; o primeiro teve início em março de 2004 e o último em dezembro de 2007 (Tabela 1). Toda a amostra foi composta por ações de rito comum ordinário propostas por 4 diferentes advogados particulares; não foram identificados processos conduzidos pela Defensoria Pública nem tampouco pelo Ministério Público.

Dos 13 processos, apenas um apresentou pluralidade no polo ativo (litisconsórcio ativo facultativo), totalizando 8 autores, todos participantes de estudo clínico financiado por uma das indústrias farmacêuticas que produzem o medicamento para doença de Fabry. No momento da propositura da ação coletiva, os demandantes ainda estavam recebendo do laboratório o medicamento de forma gratuita, mas alegavam a iminência do final do contrato que interromperia o tratamento iniciado. Três destes oito demandantes (F, G, H, Tabela 1) optaram por também ajuizar, cada um, ações individuais contra réus diferentes do processo coletivo, muito provavelmente com o intuito de garantir a sua pretensão contra ao menos um ente público. Como estas três ações contaram com a União no polo passivo, foram distribuídas para a Justiça Federal. Além disso, estão incluídas nas 13 identificadas pela pesquisa.

As ações foram propostas por 17 demandantes $($ sexo masculino $=13)$, todos residentes no RS, sendo 1 morador da capital Porto Alegre e 16 residindo em outros 8 municípios do estado. A média de idade foi de 35,6 anos (amplitude $=16$ - 
Tabela 1. Acesso à terapia de reposição enzimática para doença de Fabry no Rio Grande do Sul: andamento processual das demandas judiciais.

\begin{tabular}{|c|c|c|c|c|}
\hline Processo & Demandantes & $\begin{array}{c}\text { Andamento processual até } \\
\text { análise da equipe de } \\
\text { pesquisa (dias) }\end{array}$ & $\begin{array}{l}\text { Andamento } \\
\text { processual até } \\
\text { liminar* (dias) }\end{array}$ & $\begin{array}{l}\text { Andamento } \\
\text { processual até } \\
\text { sentença (dias) }\end{array}$ \\
\hline & A & & & \\
\hline & B & & & \\
\hline & $\mathrm{C}$ & & & \\
\hline & $\mathrm{D}$ & & & \\
\hline \multirow[t]{4}{*}{1} & $\mathrm{E}$ & 875 & 10 & 637 \\
\hline & F & & & \\
\hline & G & & & \\
\hline & $\mathbf{H}$ & & & \\
\hline 2 & I & 764 & 0 & ET \\
\hline 3 & $\mathrm{~J}$ & 406 & 0 & 149 \\
\hline 4 & K & 348 & 27 & ET \\
\hline 5 & $\mathrm{~L}$ & 338 & 1 & ET \\
\hline 6 & M & 281 & 54 & $\mathrm{ET}$ \\
\hline 7 & $\mathrm{~N}$ & 266 & 7 & ET \\
\hline 8 & $\mathbf{F}$ & 195 & 30 & ET \\
\hline 9 & G & 178 & 1 & ET \\
\hline 10 & $\mathbf{H}$ & 139 & 50 & ET \\
\hline 11 & $\mathrm{O}$ & 76 & 0 & $\mathrm{ET}$ \\
\hline 12 & $\mathrm{P}$ & 35 & 0 & ET \\
\hline 13 & Q & 28 & 1 & ET \\
\hline Mediana & - & $266\left(269,5^{* *}\right)$ & $1\left(28,5^{* *}\right)$ & - \\
\hline
\end{tabular}

*Foi considerada a data da assinatura do juiz e não da publicação da decisão. ${ }^{* *}$ Intervalo interquartil. Os pacientes F, G e H eram demandantes em dois processos. ET = Em tramitação (sem sentença no momento da análise da equipe executora).

62). Informação sobre ocupação estava disponível para 14 deles, cujos termos exatos utilizados pelos advogados foram: dois "beneficiários da Previdência Social” (ambos sem idade informada), dois "inválidos" (idade $=38$ e 48 anos, respectivamente), dois "aposentados" (idade $=41 \mathrm{e}$ 62 , respectivamente), dois "estudantes" (idade = 16 e 18 anos, respectivamente), um "pensionista" (idade $=42$ anos), um “do lar" (idade $=41$ anos), um “desempregado" (idade não informada), um "vigilante" (idade = 29 anos), um "ajudante de cozinha” (idade não informada) e um "industriário" (idade $=21$ anos). Os 17 demandantes solicitaram e obtiveram Assistência Judiciária Gratuita, medida concedida pelo juiz da causa que isenta a parte de pagar as custas iniciais do processo e eventuais honorários para o advogado da parte contrária.

Em relação à prescrição do tratamento, onze demandantes solicitaram o medicamento alfagalsidase e 6 solicitaram betagalsidase. O custo médio das solicitações judiciais de ambas as enzimas, para tratamento anual de um paciente, foi de R\$326.686,00 (trezentos e vinte e seis mil seiscentos e oitenta e seis reais). A especialidade do médico prescritor foi dividida entre nefrologista $(n=7 / 17)$ e geneticista $(n=10 / 17)$. Todas as 10 prescrições feitas por médicos geneticistas estavam vinculadas a instituições universitárias. A Tabela 2 apresenta a justificativa trazida pelo médico ao prescrever o tratamento, juntamente com as razões do advogado da parte autora para a propositura da ação. Importante ressaltar que quase a totalidade dos argumentos deriva do formulário semiestruturado e não são equivalentes para o advogado e para o médico. Em relação ao argumento "risco de morte", os 4 diferentes advogados o alegaram nas 13 ações.

O polo passivo das demandas (réus) foi formado por todas as combinações entre o estado do Rio Grande do Sul, a União e municípios gaúchos (estes totalizando 4). A Tabela 3 demonstra estas configurações, bem como as mudanças ocorridas durante a instrução dos processos. Ao final dessas mudanças, cinco processos foram direcionados contra a União - de forma isolada ou em conjunto com outro ente público.

Por fim, no processo coletivo houve pedido do Estado do Rio Grande do Sul de chamamento da indústria farmacêutica financiadora da pes- 
Tabela 2. Acesso à terapia de reposição enzimática para doença de Fabry no Rio Grande do Sul: argumentos utilizados pelo médico na prescrição do medicamento e argumentos do advogado da parte autora para a propositura da ação judicial ( $\mathrm{n}=13$ ações).

Argumentos utilizados pelo médico prescritor

Melhora da qualidade de vida

Risco de morte

Ausência de outras formas de tratamento

Aumento da sobrevida

Existência de ensaio clínico fase III randomizado contra placebo envolvendo o medicamento solicitado

Outros ${ }^{* *}$

Reversão do comprometimento renal 3

Prevenção de complicações

Reversão do comprometimento sistêmico da doença 1

Segurança da medicação 11

Participação em estudo clínico envolvendo o medicamento solicitado 1

Argumentos utilizados pelo advogado da parte autora

Aspectos gerais

Existência de prescrição médica $\quad 13$

Risco de morte 13

Possível demora ou negativa por parte do réu em relação ao fornecimento do medicamento 6

por via administrativa

Negativa anterior do réu em relação a pedido administrativo $\quad 1$

Aspectos legais e constitucionais

Direito à saúde

Dignidade humana

Princípio da igualdade

Outros $^{* *}$

Lei Estadual (RS) no 9.908/93 (medicamentos excepcionais) 2

Direito à vida

"Mais de um argumento poderia ser utilizado por ação. ${ }^{* *}$ Argumentos relevantes, não previstos inicialmente no formulário padrão, mas que foram citados nas ações.

Tabela 3. Acesso à terapia de reposição enzimática para doença de Fabry no Rio Grande do Sul: formação do polo passivo (réus) das demandas judiciais, de acordo com o número de processos em que cada ente público aparece e as diferentes configurações.

\begin{tabular}{lccccccc}
\hline \multicolumn{1}{c}{ Momento do processo } & $\mathbf{U}$ & $\mathbf{E}$ & $\mathbf{M}$ & $\mathbf{U} / \mathbf{E}$ & $\mathbf{U} / \mathbf{M}$ & $\mathbf{E} / \mathbf{M}$ & $\mathbf{U} / \mathbf{E} / \mathbf{M}$ \\
\hline Petição inicial & 3 & 5 & 1 & 2 & 0 & 2 & 0 \\
Em definitivo/após saneamento & 1 & 5 & 0 & 2 & 1 & 2 & 2 \\
\hline
\end{tabular}

$\mathrm{U}=$ União; $\mathrm{E}=$ Estado $; \mathrm{M}=$ Município.

quisa clínica ao processo. O Juiz da causa negou este pedido, por entender que a situação não se enquadrava nas hipóteses legais do Código de Processo Civil e porque, diante da complexidade e urgência da causa, o alargamento do polo passivo poderia resultar em demora prejudicial aos demandantes.

\section{Tramitação e decisões judiciais}

Em todos os 13 processos houve pedido de liminar em antecipação de tutela, para que o medicamento fosse fornecido no decorrer da tramitação, sendo que em apenas dois houve indeferimento em primeira instância. 
$\mathrm{O}$ indeferimento em um destes pedidos deuse pelo argumento da parte ser, na época, beneficiária de sentença procedente no processo coletivo, pois, além deste processo individual, fazia parte do grupo de oito demandantes do processo coletivo. Os dois outros demandantes que optaram por ajuizar processos individuais, além do coletivo, obtiveram liminar de concessão do medicamento, sob o argumento de que a sentença de procedência da ação, da qual também faziam parte, tivera seus efeitos suspensos devido a recurso de apelação recebido no efeito suspensivo.

Até o período de análise da equipe, apenas dois processos haviam sido sentenciados, ambos procedentes, para fornecer o medicamento conforme solicitado na petição inicial.

Somente no processo 3 (Tabela 1) houve pedido de perícia médica, efetuado pelo réu Estado do Rio Grande do Sul. O pedido não foi apreciado pelo juiz da causa no decorrer da instrução probatória e tampouco fora mencionado na sentença.

As Tabelas 4 e 5 trazem a incidência dos argumentos utilizados nas sentenças e nas decisões liminares, havendo maior prevalência de argumentos sobre a existência de laudos médicos receitan- do o medicamento e de garantias constitucionais do direito à saúde, que aqui representam o art. 196 da Constituição Federal de 1988 e da Lei no 8.080 de 1990 (Sistema Único de Saúde - SUS).

\section{Discussão}

As inovações constitucionais relativas à previsão da saúde como direito fundamental social e a ausência de uma política pública de saúde capaz de concretizar os princípios da universalidade e da integralidade contribuíram para o desenvolvimento do chamado fenômeno da judicialização da saúde, onde demandas ao Judiciário passaram a buscar a satisfação de necessidades não atendidas pelo Estado, em que pese a sua atribuição para tanto. Trata-se em verdade de consequência do fenômeno mais amplo da judicialização da política, cujo acesso à justiça para a garantia de direitos de cidadania converteu-se em verdadeira política pública.

A democratização deste acesso permitiu, também, um maior controle da atividade parlamentar, reforçando o processo de deliberação através

Tabela 4. Acesso à terapia de reposição enzimática para doença de Fabry no Rio Grande do Sul: comparação entre os argumentos utilizados pelo juiz nas decisões liminares

\begin{tabular}{|c|c|c|}
\hline Argumentos utilizados pelo juiz & $\begin{array}{c}\text { Favoráveis } \\
(\mathbf{n}=10)^{*}\end{array}$ & $\begin{array}{l}\text { Desfavoráveis } \\
\qquad(\mathbf{n}=2)^{*}\end{array}$ \\
\hline \multicolumn{3}{|l|}{ Aspectos médicos e de pesquisa } \\
\hline Existência de laudos médicos & 10 & 0 \\
\hline Protocolos do Ministério da Saúde & 0 & 0 \\
\hline Participação em protocolos de pesquisa envolvendo medicamento solicitado & 0 & 2 \\
\hline Risco de morte & 1 & 0 \\
\hline \multicolumn{3}{|l|}{ Outros ${ }^{* *}$} \\
\hline Parte beneficiária de liminar em processo diverso & - & 1 \\
\hline Ausência de registro do medicamento na ANVISA & - & 1 \\
\hline \multicolumn{3}{|l|}{ Aspectos econômicos } \\
\hline Previsão e impacto no orçamento público & 0 & 0 \\
\hline Ética dos recursos escassos & 0 & 1 \\
\hline Custo-efetividade & 0 & 0 \\
\hline \multicolumn{3}{|l|}{ Aspectos legais e constitucionais } \\
\hline Direito à saúde & 11 & 0 \\
\hline Dignidade humana & 2 & 0 \\
\hline Reserva do possível/princípio da proporcionalidade & 0 & 0 \\
\hline $\begin{array}{l}\text { Discricionariedade da Administração Pública/princípio da separação dos } \\
\text { poderes }\end{array}$ & 0 & 0 \\
\hline Princípio da igualdade & 0 & 0 \\
\hline \multicolumn{3}{|l|}{ Outros $^{\star *}$} \\
\hline Estatuto do Idoso & 1 & - \\
\hline
\end{tabular}

"Mais de um argumento poderia ser utilizado por ação. "Argumentos relevantes, não previstos inicialmente no formulário padrão, mas que foram citados nas ações. 
Tabela 5. Acesso à terapia de reposição enzimática para doença de Fabry no Rio Grande do Sul: comparação entre os argumentos utilizados pelo juiz nas sentenças $(n=2)$, ambas julgadas procedentes.

Argumentos utilizados pelo juiz $\quad \begin{gathered}\mathbf{n}^{*} \\ \text { (sentença 1) }\end{gathered} \quad \begin{gathered}\mathbf{n}^{*} \\ \text { (sentença 2) }\end{gathered}$

\begin{tabular}{|c|c|}
\hline \multicolumn{2}{|l|}{ Aspectos médicos e de pesquisa } \\
\hline Existência de laudos médicos & 1 \\
\hline Protocolos do Ministério da Saúde & 0 \\
\hline Participação em protocolos de pesquisa envolvendo medicamento solicitado & 1 \\
\hline Risco de morte & 0 \\
\hline \multicolumn{2}{|l|}{ Aspectos econômicos } \\
\hline Previsão e impacto no orçamento público & 0 \\
\hline Ética dos recursos escassos & 0 \\
\hline Custo-efetividade & 0 \\
\hline \multicolumn{2}{|l|}{ Aspectos legais e constitucionais } \\
\hline Direito à saúde & 1 \\
\hline Dignidade humana & 0 \\
\hline Reserva do possível/princípio da proporcionalidade & 0 \\
\hline $\begin{array}{l}\text { Discricionariedade da Administração Pública/princípio da separação dos } \\
\text { poderes }\end{array}$ & 0 \\
\hline Princípio da igualdade & 0 \\
\hline \multicolumn{2}{|l|}{ Outros ${ }^{* *}$} \\
\hline Direito à vida & - \\
\hline Lei Estadual (RS) no 9.908/93 (medicamentos especiais) & 1 \\
\hline
\end{tabular}

${ }^{*}$ Mais de um argumento poderia ser utilizado por ação. ${ }^{* *}$ Argumentos relevantes, não previstos inicialmente no formulário padrão, mas que foram citados nas ações.

de um canal alternativo de participação política. Deste modo, a atividade jurisprudencial do direito tem o poder de formar novos direitos ou de corrigir omissões administrativas, pois as rápidas transformações sociais nem sempre são acompanhadas de perto pela atividade legislativa ${ }^{9}$.

Ocorre que esta judicialização do acesso ao tratamento de doenças genéticas raras, exemplificadas neste estudo pela doença de Fabry, possui inúmeras questões a serem ponderadas que divergem do cenário usual do fenômeno. A exigibilidade destes direitos não pode converter os cidadãos em receptores passivos das benesses do Estado, numa espécie de "privatização da cidadania" ${ }^{10}$, sem que haja uma política que enfrente os aspectos bioéticos, médicos, econômicos e jurídicos caracterizadores deste debate.

Os benefícios clínicos da utilização da Terapia de Reposição Enzimática (TRE) em pacientes com doença de Fabry podem ser considerados um assunto ainda em discussão. Os primeiros ensaios clínicos controlados realizados quando estes medicamentos foram lançados no mercado basearam-se em desfechos não-clínicos como a redução dos níveis de Gb3 no plasma, urina e tecidos $^{11,12}$. Posteriormente, surgiram estudos de coorte/seguimento que indicaram benefícios clí- nicos em aspectos como a diminuição na frequência das crises de dor, redução da massa ventricular esquerda e na estabilização da função renal. Uma apreciação crítica destes estudos revela, no entanto, que os benefícios clínicos, apesar de possíveis, ainda não estão claramente estabelecidos. Tomemos como exemplo a literatura disponível sobre duas das mais graves consequências clínicas da doença de Fabry: a doença renal (insuficiência renal progressiva) e a doença cardíaca (hipertrofia de ventrículo esquerdo seguida de disfunção cardíaca).

Sobre o tópico função renal, analisemos três estudos recentes. Em dois deles, um de $2007^{13} \mathrm{e}$ outro de $2009^{14}$, os pesquisadores seguiram pacientes com doença de Fabry submetidos à TRE por períodos de até 54 meses e 36 meses, respectivamente. Ambos eram coortes, não controladas. No primeiro, ao final do seguimento, havia 47 pacientes; destes, 41 com função renal estável e 6 com progressão da doença renal. O segundo, que incluiu pacientes com ou sem disfunção renal prévia, mostrou função renal estável nos pacientes com doença renal crônica (fases I, II ou III). Em ambos os casos, a conclusão dos autores foi que a TRE, ao longo prazo, estabilizaria a função renal. Em contraste, em outro estudo publicado em 
2009, por Feriozzi et al. ${ }^{15}$, seguindo desenho similar (coorte não controlada), observou-se a piora da creatinina sérica em todos os indivíduos tratados com TRE. Não obstante isso, a conclusão apresentada pelos autores foi que agalsidase alfa poderia ser eficaz em retardar a deterioração da função renal na nefropatia de Fabry.

No que tange à disfunção cardíaca, os resultados (e a interpretação destes) não são também inequívocos. Estudo de Weidemann et al. ${ }^{16}$ seguiu pacientes submetidos à TRE por mais um período de 3 anos e avaliou a hipertrofia ventricular esquerda. Os resultados apontaram a redução na hipertrofia do ventrículo esquerdo e uma tendência na melhora na capacidade de exercício, mas isto foi observado apenas em um pequeno subgrupo de pacientes sem sinais prévios de fibrose miocárdica ( $\mathrm{n}=12 / 32$ dos casos). Uma publicação de Imbriaco et al. ${ }^{17}$, avaliou pacientes submetidos à TRE por até 45 meses; do ponto de vista cardíaco, mostrou-se redução na hipertrofia do ventrículo esquerdo, sem que, no entanto, houvesse mudanças significativas na fração de ejeção.

Quanto aos efeitos adversos dos dois produtos, os mais comuns são reações de infusão, seguidas de cefaleia, tremor e distúrbios gastrintestinais. A maioria destes não é grave, mas não há também dados sobre a segurança do uso ao longo prazo dos mesmos.

O aspecto central para os profissionais de saúde, quando se decide tratar (ou não) um paciente, é a relação risco-benefício do tratamento em questão. Considerando-se a TRE na doença de Fabry, ainda há incertezas relacionadas aos possíveis benefícios e aos riscos do tratamento, e isto não pode ser desconsiderado.

A Medicina Baseada em Evidências (MBE) pode constituir uma tentativa de diálogo que considere estas incertezas sobre o tratamento específico da doença de Fabry e a judicialização do acesso ao tratamento. Originada na Universidade de MacMaster, no Canadá, no início da década de 80 , esta prática consiste em avaliar toda intervenção médica de acordo com as melhores evidências existentes, obtidas em experimentos científicos bem conduzidos, com o intuito de reduzir a incerteza na tomada de decisão em saú$\mathrm{de}^{18}$. Sua abordagem utiliza as ferramentas de quatro áreas distintas: epidemiologia clínica, metodologia científica, estatística e informática.

Para sua eficiente utilização, a Organização Mundial de Saúde (OMS) aconselha que devam existir recomendações e diretrizes clínicas atualizadas que orientem a conduta médica. A primeira iniciativa no Brasil ocorreu em 2002 através do MS, com a publicação dos "Protocolos Clínicos e Diretrizes Terapêuticas" (PCDT) para vários dos chamados medicamentos excepcionais (atualmente parte do componente especializado de Assistência Farmacêutica do MS) ${ }^{19}$. A maioria dos medicamentos para doenças genéticas, incluídos na lista de componentes especializados, apresenta PCDT publicado.

Outra contribuição importante ao processo de judicialização marcado pelas incertezas do tratamento da doença de Fabry vem da ATS. Ela envolve a avaliação sistemática de todas as tecnologias da área da saúde, as quais podem incluir procedimentos, equipamentos e drogas que são aplicadas na manutenção, promoção e restauração da saúde. Com base em informações objetivas, a ATS subsidia a elaboração de políticas na área da saúde e os gestores do sistema de saúde, inclusive sobre a inclusão, ou exclusão, de determinada tecnologia em programas e listas de fornecimento. A decisão para a incorporação de novas tecnologias baseia-se nos critérios de eficácia, segurança, custo-efetividade e impacto financeiro ${ }^{20,21}$.

Os dados ora obtidos conduzem a uma dúplice discussão: por um lado, existem deficiências na maneira como as ações judiciais têm tramitado, sendo importante, para a eficiência do acesso ao tratamento da doença de Fabry, alertar para questões pontuais neste processo; conjuntamente, faz-se necessária uma avaliação sobre a atuação do Judiciário e suas consequências para a gestão de uma política pública relativa às doenças genéticas raras.

Embora poucas informações constem dos processos - o que não permitiu traçar um perfil mais exato dos demandantes, visto que dados como naturalidade, escolaridade e renda são praticamente ausentes -, outros dados indicam um perfil de hipossuficiência dos mesmos. A simples verificação das ocupações informadas leva a esta conclusão. No mesmo sentido, todos postularam e receberam Assistência Judiciária Gratuita, medida que isenta do pagamento das custas processuais; e seja pela verificação dos sobrenomes ou pela análise do conteúdo dos processos, dados confirmaram o parentesco entre 6 demandantes, indicando semelhança do perfil socioeconômico.

Ainda em relação a este perfil, nota-se que há seis demandantes alegando situação de aposentadoria, dependência de benefício ou invalidez, embora algumas das idades correspondentes poderiam não sugerir, em condições normais, tal situação (invalidez aos 38 e aos 48 anos de idade; aposentadoria aos 41 anos). Isto pode indicar que a situação resulta do quadro clínico causado pela doença. 
Já em relação ao perfil demográfico dos demandantes, a prevalência de indivíduos do sexo masculino e de adultos jovens encontra-se em consonância com os aspectos epidemiológicos descritos na doença de Fabry, embora o pequeno número de casos avaliados não nos permita uma confirmação inequívoca deste fato. Também, o momento da solicitação do acesso ao tratamento por via judicial parece acompanhar o período de surgimento das complicações da doença (adultos jovens).

Percebe-se que todos os processos, mesmo o que envolve 8 demandantes, versam sobre pedidos individuais de medicamentos, não havendo argumentação sobre inclusão dos medicamentos em listas de dispensação, ou tampouco padronização e universalização do acesso.

$\mathrm{O}$ primeiro processo iniciou em março de 2004, justamente porque o tratamento disponível era ainda recente (a primeira aprovação mundial de medicamento para esta doença ocorreu em 2003). Entretanto, no período da pesquisa, a enzima betagalsidase fora registrada na Anvisa, o que permitia se pensar em demandas de eficácia coletiva, como para sua inclusão em listas de dispensação do MS.

Este caráter individualista é também evidenciado pelo fato de que 3 demandantes do processo com 8 demandantes contra o Estado do Rio Grande do Sul, já beneficiários de sentença procedente, ajuizaram paralelamente ações contra a União. Nestes casos, corre-se o risco de se fornecer duplamente um medicamento de alto custo. Como se observa nos resultados, estes 3 litigantes obtiveram liminares em sentidos diversos com argumentação contraditória dos Magistrados: para negar uma delas, o juiz responsável entendeu que a sentença do processo coletivo estava sendo cumprida, portanto deveria ser evitada a duplicidade de fornecimento; já para conceder as outras duas liminares, os juízes respectivos alegaram que a sentença estava suspensa por recurso de apelação interposto pelo réu, portanto nova concessão de liminar não resultaria em duplo fornecimento pelo estado e pela União, ao menos enquanto perdurasse a suspensão da sentença.

Outra constatação referente à formação dos processos é quanto ao polo passivo (réus). A inclusão de algum réu no curso do processo - além daquele inicialmente identificado pelo advogado da parte autora como o responsável pelo fornecimento do tratamento - se mostrou a tendência das várias modificações. Porém, estas modificações não foram motivadas por uma avaliação da parte autora de que demandara contra o ente público errado; o que ocorreu foi a reiterada alegação de irresponsabilidade por parte do ente público ao qual originalmente foi distribuída a ação (municípios, estado e União), utilizando o instrumento processual do "chamamento ao processo" dos outros entes públicos.

Apenas um processo foi dirigido unicamente contra algum município, mas, ao final, nenhuma ação contou com esta configuração no polo passivo. Isto pode sugerir a percepção por parte dos autores de que o alto custo dos medicamentos solicitados indica que estes devam ser pleiteados aos estados e à União ou, ao menos, a uma pluralidade de réus que inclua algum destes dois entes públicos.

Mesmo assim, parece não haver consenso sobre as competências da União, estados e municípios em matéria de saúde. Segundo a Portaria GM/MS no 2.577, de 27 de outubro de 2006, que regulamentava o antigo Componente de Medicamentos de Dispensação Excepcional da Assistência Farmacêutica $(\mathrm{CMDE})^{5}$, vigente à época dos processos analisados, os medicamentos excepcionais eram financiados principalmente pelos estados e excepcionalmente pela União (através da Portaria $n^{\circ} 2.981$, de 2009, o CMDE deu lugar ao Componente Especializado da Assistência Farmacêutica ${ }^{22}$. Ainda, a recente Lei 12.401/ 2011, que altera a Lei 8080/90, reforça o papel das listas Nacional e Estaduais de Medicamentos e dos $\mathrm{PCDT}^{23}$. Estes medicamentos, ao contrário dos considerados essenciais - cuja aquisição e dispensação compete aos municípios -, possuem alto valor unitário, devido à baixa prevalência da doença, ou se destinam ao tratamento de doenças crônicas, o que eleva o custo total do tratamento. No caso deste estudo, aplicam-se as duas características.

Portanto, o correto direcionamento das demandas poderia contribuir para com a celeridade processual, além de evitar onerar desnecessariamente os cofres de municípios não habilitados legal e financeiramente para o fornecimento de medicamentos de alto custo.

Em relação à prescrição do tratamento, notase que ambos os medicamentos foram receitados e pleiteados judicialmente, embora apenas a betagalsidase possuísse registro na Anvisa à época do estudo, mas sem que fosse previsto em qualquer lista de dispensação gratuita. Em que pese esta restrição, ambos os medicamentos já estavam aprovados por agências de regulação sanitária estrangeiras.

Há, entre os demandantes, maior frequência de solicitação por alfagalsidase (11 de 17), enquan- 
to que monitoramento anterior abrangendo pacientes de todo o Brasil (ver introdução) concluiu que a maioria dos tratados vinha recebendo betagalsidase (14 de 22). Esta contradição perde a importância em virtude do tamanho amostral do presente estudo: como há 8 de 17 demandantes litigando em uma mesma ação, eles tendem a pleitear o mesmo medicamento, ainda mais porque, neste caso, vinham recebendo por acesso expandido de laboratório que produz somente a alfagalsidase. Sendo assim, não há como tecer conclusões generalizantes acerca da suposta prevalência regional e nacional das prescrições médicas.

Das 11 prescrições de alfagalsidase, 6 tiveram origem em instituição universitária. Este dado comprova que os hospitais universitários, devido ao avanço científico de suas pesquisas, tendem a receitar novas tecnologias. Outro aspecto que pode também estar associado a este achado é o fato de a maioria dos pacientes com diagnósticos de doenças genéticas raras possuírem acompanhamento em centros de alta complexidade, como os hospitais universitários. Entretanto, uma vez que estes centros não fornecem estes medicamentos não padronizados, podem colaborar na geração de distorções no sistema e ajudar no condicionamento do seu acesso através de mandados judiciais. Estas conclusões são similares àquelas obtidas em outros estudos sobre assistência farmacêutica e mandados judiciais ${ }^{24}$.

Da mesma forma que hospitais universitários detêm novas tecnologias, laboratórios financiadores de pesquisas inovadoras também são potenciais condicionadores indiretos da busca judicial pela continuidade do tratamento recebido em pesquisas clínicas. Como se comprovou no processo coletivo analisado, existiu ameaça da cessação do fornecimento do medicamento que vinha até então sendo fornecido diretamente pelo laboratório produtor no contexto de um programa de pesquisa, o que traz a necessidade de se pensar nas questões éticas que envolvem as pesquisas em portadores de doenças crônicas, ou seja, que necessitam indefinidamente da medicação.

Evidente, também, que a falta de registro no país é forte argumento de defesa do ente público réu para o não fornecimento do medicamento ao paciente, especialmente quando a instrução do processo não apresenta documentação que comprove a existência de estudos de eficácia da droga requerida, limitando-se a argumentos sobre garantias constitucionais. Ambas as enzimas possuem aprovação em agências estrangeiras e constituem o único tratamento conhecido; tais informações deveriam vir ao processo.
Por outro lado, a falta de aspectos médicos instruindo as ações tende a beneficiar os demandantes e a comprometer a eficiência e correção do processo judicial como um todo. $\mathrm{O}$ argumento "risco de morte", mesmo constituindo um dado clínico passível de comprovação científica, é usado para convencimento do Juízo sem que haja correspondência na respectiva prescrição médica. Isto influencia o magistrado a decidir positivamente sobre eventual pedido liminar, já que os requisitos para a concessão antecipada são baseados na urgência e na verossimilhança da alegação. Consequentemente, tem-se o fornecimento de medicamentos de alto custo sem a devida comprovação médica da necessidade imediata, onerando de forma definitiva e talvez desnecessária o Estado.

É preciso, portanto, incorporar aspectos da MBE nas discussões judiciais para que se garanta o fornecimento de medicamentos seguros e eficazes. Como o processo de rito comum ordinário possui cognição plena - ampla instrução a partir de todos os tipos de prova -, tornando seu ciclo lento até que se tenha uma sentença, o fornecimento do medicamento fica condicionado à concessão de liminar. Este é outro motivo pelo qual as decisões antecipadas precisam basear-se nas melhores evidências científicas.

Os resultados apontam também para questões relativas à argumentação utilizada nas decisões, tanto liminares quanto sentenças. A mediana de 266 dias de tramitação até análise da equipe, inferior a um ano, é refletida na escassez de sentenças (apenas duas), embora o fornecimento do medicamento em caráter temporário, através de liminar, seja garantido em curto tempo. Deste modo, em geral, foram analisados processos novos sem maiores discussões sobre o mérito. De qualquer forma, há pouca menção sobre argumentos econômicos e princípios que conduziriam a uma discussão mais qualificada acerca de doenças raras, eficácia do tratamento, medicamentos de alto custo e impacto orçamentário.

Esta ausência de argumentos econômicos contraria a própria natureza dos medicamentos órfãos e doenças raras. O único estudo sobre TRE para a doença de Fabry é o de Connock et al. ${ }^{25}$, cujos resultados concluíram que este tratamento não é custo-efetivo. Consequentemente, o alto custo dos medicamentos e as limitações orçamentárias não demonstradas não podem constituir os únicos critérios de avaliação para o acesso a estes tratamentos; as decisões judiciais precisam enfrentar questões de ética na alocação de recursos escassos e qualificar as discussões sobre doenças raras. 
Obviamente, a chamada cognição sumária das liminares - onde são analisados menos requisitos para a concessão do medicamento, já que se trata de decisão temporária e, teoricamente, reversível - reduz a argumentação para questões menos complexas. É o que de fato constatou-se: as decisões judiciais favoráveis parecem contentar-se com a presença de prescrição médica, embora a opinião de especialista corresponda ao nível mais baixo de evidência científica sobre a eficácia e segurança da tecnologia requisitada ${ }^{26,27}$.

Conclui-se, por fim, que as ações judiciais analisadas possuem importância instrumental no contexto da democratização do acesso ao tratamento da doença de Fabry, pois formam um canal alternativo de vocalização das necessidades sociais já antes existentes, o que permite verificar a real necessidade, segurança e eficácia do medicamento/tratamento solicitado. $\mathrm{O}$ acesso a medicamentos de alto custo e que não fazem parte de listas nacionais, no nosso país, invariavelmente dá-se por ações judiciais individuais. Contudo, é este fenômeno que leva à reflexão e à pressão por uma política específica para doenças raras. A intervenção do Poder Judiciário não necessariamente elabora políticas públicas, ele antes corrige omissões do processo legislativo de assuntos que não podem depender apenas da maioria parlamentar, uma vez que o Legislativo e o Executivo não conseguem dar conta das demandas sociais e cumprir com o papel dado pela democracia representativa. É um processo típico do constitucionalismo moderno que precisa, necessariamente, levar a uma maior participação através de uma cidadania ativa. Isto se dá, primeiramente, pela racionalização do processo judicial e incorporação de questões técnicas às discussões dos tribunais. Como visto, não existem critérios padrão adotados por eles. Posteriormente, a judicializa- ção deve ser substituída por uma política pública que garanta acesso qualificado e igualitário ao tratamento, evitando distorções no planejamento da assistência farmacêutica.

\section{Colaboradores}

D Sartori Junior fez a análise dos processos, coleta e interpretação dos dados, elaboração do artigo. PGC Leivas foi responsável pela elaboração do projeto, interpretação dos dados, elaboração do artigo. MV Souza realizou a coleta e a interpretação dos dados primários, elaboração e execução do projeto, elaboração do artigo. BC Krug foi responsável pela elaboração e execução do projeto, elaboração do artigo. G Balbinotto fez a coleta e a interpretação dos dados primários, elaboração e execução do projeto, elaboração do artigo. IVD Schwartz elaborou o projeto e o submeteu ao comitê de ética, fez a análise e a interpretação dos dados, e participou da elaboração do artigo.

\section{Agradecimentos}

Agradecemos a imensa colaboração dos bacharéis em direito Manuel Trindade, Fernando Arenhart e Cristiano Huber na extração dos dados e nas discussões sobre os aspectos legais surgidos durante o curso daquela. Agradecemos ao Dr. Paulo D. Picon e à equipe da Procuradoria Geral do Estado do Rio Grande do Sul pelo auxílio no acesso aos dados dos processos. Este trabalho teve o apoio do CNPq/MS-SCTIE-DECIT. 


\section{Referências}

1. Desnick RJ, Brady R, Barranger J, Collins AJ, Germain DP, Goldman M, Grabowski G, Packman S, Wilcox WR. Fabry disease, an under-recognized multisystemic disorder: expert recommendations for diagnosis, management, and enzyme replacement therapy. Ann Intern Med 2003; 138(4):338-346.

2. MacDermot KD, Holmes A, Miners AH.AndersonFabry disease: clinical manifestations and impact of disease in a cohort of 98 hemizygous males. $J$ Med Genet 2001; 38(11):750-760.

3. Souza MV, Krug BC, Picon PD, Schwartz IVD. Medicamentos de alto custo para doenças raras no Brasil: o exemplo das doenças lisossômicas. Cien Saude Colet 2010; 15(3):3443-3454.

4. Wraith JE. Clinical aspects and diagnosis. In: Platt FM, Walkley SU, editors. Lysosomal disorders of the brain. Oxford: Oxford University Press; 2004. p. 50-80.

5. Brasil. Ministério da Saúde. Portaria GM/MS no 2.577 de 27 de outubro de 2006. Aprova o Componente de Medicamentos de Dispensação Excepcional. Diário Oficial da União 2006; 10 nov.

6. Silva L. Avaliação tecnológica e análise custo-efetividade em saúde: a incorporação de tecnologias e a produção de diretrizes clínicas para o SUS. Cien Saude Colet 2003; 8(2):501-520.

7. Haffner ME. Focus on Research: Adopting Orphan Drugs - Two Dozen Years of Treating Rare Diseases. N Engl J Med 2006; 354(5):445-447.

8. Brasil. Lei $\mathrm{n}^{\circ} 8.080$ de 19 de setembro de 1990. Dispõe sobre as condições para a promoção, proteção e recuperação da saúde, a organização e o funcionamento dos serviços correspondentes e dá outras providências. Diário Oficial da União 1990; 20 set.

9. Casagrande C. O Ministério Público e a judicialização da política: estudos de casos. Porto Alegre: Sérgio Antonio Fabris; 2008.

10. Vianna LW, Carvalho MAR, Melo MPC, Burgos MB. A judicialização da política e das relações sociais no Brasil. Rio de Janeiro: Revan; 1999.

11. Eng CM, Guffon N, Wilcox WR, Germain DP, Lee P, Waldek S, Caplan L, Linthorst GE, Desnick RJ, et al. Safety and efficacy of recombinant human alpha-galactosidase A- replacement therapy in Fabry's disease. $N$ Engl J Med 2001; 345(1):9-16.

12. Schiffmann R, Kopp JB, Austin HA 3rd, Sabnis S, Moore DF, Weibel T, Balow JE, Brady RO. Enzyme replacement therapy in Fabry disease: a randomized controlled trial. Jama 2001; 285(21):2743-2749.

13. Germain, D P, Waldek, S, Banikazemi,M, Bushinsky, DA, Charrow,J, Desnick, RJ, Lee,P, Loew,T, Vedder, AC, Abichandani, R, Wilcox,WR, Guffon, N. Sustained, Long-Term Renal Stabilization After 54 Months of Agalsidase-Therapy in Patients with Fabry Disease. J Am Soc Nephrol 2007; 18(5):1547-1557.

14. Thofehrn S, Netto C, Cecchin C, Burin M, Matte U, Brustolin S, Nunes AC, Coelho J, Tsao M, Jardim L, Giugliani R, Barros EJ. Kidney function and 24hour proteinuria in patients with Fabry disease during 36 months of agalsidase alfa enzyme replacement therapy: a Brazilian experience. Ren Fail 2009; 31(9):773-778.
15. Feriozzi S, Schwarting A, Sunder-Plassmann G, West M, Cybulla M, International Fabry Outcome Survey Investigators. Agalsidase alfa slows the decline in renal function in patients with Fabry disease. Am J Nephrol 2009; 29(5):353-361.

16. Weidemann F, Niemann M, Breunig F, Herrmann S, Beer M, Störk S, Voelker W, Ertl G, Wanner C, Strotmann J. Long-term effects of enzyme replacement therapy on fabry cardiomyopathy: evidence for a better outcome with early treatment. Circulation 2009; 119(4):524-529.

17. Imbriaco M, Pisani A, Spinelli L, Cuocolo A, Messalli G, Capuano E, Marmo M, Liuzzi R, Visciano B, Cianciaruso B, Salvatore M. Effects of enzyme-replacement therapy in patients with Anderson-Fabry disease: a prospective long-term cardiac magnetic resonance imaging study. Heart 2009; 95(13):1103-1107.

18. Evidence-Based Medicine Working Group. Evidence-based medicine. A new approach to teaching the practice of medicine. Jama 1992; 268(17):2420-2425.

19. Brasil. Ministério da Saúde (MS). Secretaria de Assistência à Saúde. Departamento de Sistemas e Redes Assistenciais. Protocolos Clínicos e Diretrizes Terapêuticas - Medicamentos Excepcionais. Brasília: MS; 2002. (Série A. Normas e Manuais Técnicos)

20. Novaes HMD. Avaliação de programas, serviços e tecnologias em saúde. Rev Saude Publica 2000; 34(5): 547-559.

21. Williams AH, Cookson RA. Equity-efficiency trade-offs in Health Technology Assessment. Int $J$ Technol Assess Health Care 2006; 22(1):1-10.

22. Brasil. Ministério da Saúde (MS). Portaria GM/MS no 2.981, de 26 de novembro de 2009. Aprova o Componente Especializado da Assistência Farmacêutica. Diário Oficial da União 2009; $1 \mathrm{dez}$.

23. Brasil. Lei $n^{\circ} 12.401$. Altera a Lei $n^{\circ} 8.080$, de 19 de setembro de 1990, para dispor sobre a assistência terapêutica e a incorporação de tecnologia em saúde no âmbito do Sistema Único de Saúde SUS. Diário Oficial da União 2011; 29 abr.

24. Messeder AM, Osório-de-Castro CGS, Luiza VL. Mandados judiciais como ferramenta para garantia do acesso a medicamentos no setor público: a experiência do Estado do Rio de Janeiro, Brasil. Cad Saude Pública 2005; 21(2):525-534.

25. Connock M, Juarez-Garcia A, Frew E, Mans A, Dretzke J, Fry-Smith A, Moore D. A systematic review of the clinical effectiveness and cost-effectiveness of enzyme replacement therapies for Fabry's disease and mucopolysaccharidosis type 1. Health Technol Assess 2006; 10(20):1-130.

26. Evidence-Based Medicine Working Group. Evidence-based medicine: a new approach to teaching the practice of medicine. Jama 1992; 268(17):24202425.

27. Gugiu PC, Gugiu MR. A critical appraisal of standard guidelines for grading levels of evidence. Eval Health Prof 2010; 33(3):233-55.

Artigo apresentado em 13/05/2011

Aprovado em 01/07/2011

Versão final apresentada em 10/07/2011 